\title{
Wellbore trajectory optimization for horizontal wells: the plan versus the reality
}

\author{
Mohamed Halafawi and Lazăr Avram \\ Petroleum-Gas University of Ploiesti, Romania
}

Correspondence: Drd. Ing. Mohamed Halafawi, Petroleum-Gas University of Ploiesti, Romania, Email halafawi_2008@yahoo.com

Received: December 03, 2018 | Published: February 05, 2019

Copyright@ 2019 Halafawi et al. This is an open access article distributed under the terms of the Creative Commons Attribution License, which permits unrestricted use, distribution, and reproduction in any medium, provided the original author and source are credited.

\begin{abstract}
Horizontal wellbore profile and trajectory optimization without hole problems are considered the most essential part in well planning and design. In this paper, a long radius horizontal well was trajectory optimized by selecting horizontal profile, kick off point (KOP), horizontal turn trajectory, vertical turn determination, and mud weights. After that, in order to design 3D profile, the Minimum Curvature Method (MCM)was used for survey determination. Moreover, the best well orientation was selected based on rock mechanics and wellbore stability so that the optimum trajectory could be drilled without instability problems. Real horizontal well passed through 5 targets: NRQ $2556 \mathrm{H}-1$, NRQ 255 6H-2, NRQ $2556 \mathrm{H}-3$, NRQ $2556 \mathrm{H}-4$, and NRQ $2556 \mathrm{H}-5$ are studied. The planned trajectory has found the same as real trajectory until $95 / 8$ " casing is landed to true vertical depth (TVD) $=7230 \mathrm{ft}$. and measured depth (MD) $=7343.6 \mathrm{ft}$. However, during drilling 8.5 " hole, it was impossible to continue drilling due to the drillstring being stuck because of caved shale and hole pack off. Wellbore trajectory was redesigned and selected after building new wellbore stability and geomechanical stress models using logging while drilling (LWD) data. A 6" sidetrack hole was successfully drilled and hit the five targets horizontally.
\end{abstract}

Keywords: Horizontal well, trajectory optimization, minimum curvature, wellbore stability, hole stresses

\section{Introduction}

Wellbore trajectory planning is essential for designing directional and horizontal drilling. Its importance appears especially in cases of multi-well platforms in which a number of aspects have to be carefully examined before designing the final well path to target. Fundamental mathematical formulations to express changes in the vertical and horizontal planes, wellbore curvature, dogleg severity calculations, directional-well profiles, Horizontal Well Profiles, and three-dimensional well profiles for a wellbore trajectory were presented by Azar and Samuel, ${ }^{1}$ Mitchell, ${ }^{2}$ Bourgoyn, ${ }^{3}$ Hossain and Al-Majed, ${ }^{4}$ Rabia, ${ }^{5}$ and Mitchell and Miska. ${ }^{6}$ For wellbore trajectory planning, a quite number of important terms are used:KOP,TVD, MD, end of buildup (EOB), hold angle, the tangent sections, start of drop, end of drop, target displacement, target location, drop off rate (DOR), build up rate (BUR), turn rate, dog-leg severity (DLS), horizontal displacement (HD), vertical section (VS), geographic north, grid north, magnetic north, horizontal turn rate, hole inclination $(\phi)$, azimuth angle ( $)$, direction angle, coordinates of surface and targets, and declination angle. In well-trajectory design, the targets are usually determined by the geologist with acceptable tolerance (e.g. a circle of radius 100 feet having the target as its center). In order to reach the target, target zones must be selected as large as possible. If there are multiple zones to be reached, the planned trajectory should be reasonable and be achieved without causing drilling problems, such as those experienced in our case study. ${ }^{4}$

A good understanding of the definitions of the above terms, their derivatives and calculations, is essential for selecting good practical directional profilesand for overcoming the resulting problems.
In this paper, horizontal wellbore trajectory is going to be optimized by selecting improved horizontal hole profile, KOP, horizontal turn trajectory, vertical turn determination, mud density, and the best surveying method which is suitable for building 3D profiles. Additionally, wellbore stability analysis models, geomechanical earth models (GEM), and stress determination have to be taken in consideration in order to choose the best orientation for wellbore that yields no major hole problems.

\section{Horizontal well profiles}

Horizontal wells are drilled through curved sections up to a $90^{\circ}$ angle and then horizontally into the formation. In practical applications, horizontal well inclination angles are approximately 80 to $100^{\circ}$. In an ideal horizontal well, the inclination angle is $90^{\circ}$. The three pattern classifications of horizontal holes are short (with a radius of curvature $30-200 \mathrm{ft}$.), medium $(200-1,000 \mathrm{ft}$.), and long turn radius $(1,000-3,000 \mathrm{ft}$.) patterns. There are also ultrashort-radius systems in which high-pressure jetting techniques are used to turn the well from a vertical to a horizontal orientation..$^{1-5}$ In general, the main factors affecting a horizontal-well profile were presented by Mitchell and Miska. ${ }^{6}$

Horizontal well profile (Figure 1) consists of a vertical segment, a first buildup segment, a tangent part, and a second buildup segment, followed by a horizontal section. Here, the departure is defined as the displacement from vertical until the well reaches the beginning of the horizontal section. Horizontal displacement is the sum of the length of the horizontal section and the departure. Some horizontal wells consist of one build section connecting the vertical part with a 
horizontal section. The mathematical trajectory planning calculations and equations are the same as those used in directional calculations presented by Azar and Samuel, ${ }^{1}$ Mitchell, ${ }^{2}$ Bourgoyn, ${ }^{3}$ Hossain and Al-Majed, ${ }^{4}$ Rabia, ${ }^{5}$ and Mitchell and Miska. ${ }^{6}$ However, there is an exception that the primary unknown in the combination trajectory plan is the depth of KOP. Additionally, other problems appeared in horizontal turn trajectory, vertical turn computations, mud weight selection, 3D profile building and survey methods selection are addressed in the following sections.

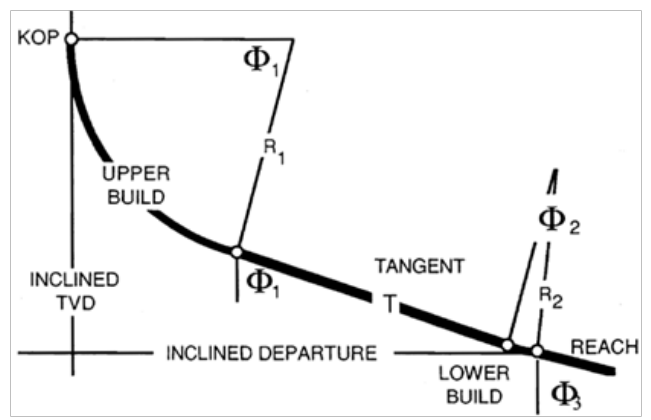

Figure I Horizontal well profile. ${ }^{2}$

KOP, horizontal turn trajectory, and verticalturn determination

Mitchell ${ }^{2}$ presented the mathematical equations for calculating KOP in the combination trajectory horizontal well planning as follows:

$$
\begin{aligned}
& \text { Inclined TVD }=R_{1} \sin \varphi_{1}+T \cos \cos \varphi_{1}+R_{2}\left(\sin \varphi_{3}-\sin \varphi_{1}\right) \\
& \text { Inclined } D E P=R_{1}\left(1-\cos \varphi_{1}\right)+T \sin \sin \varphi_{1}+R_{2}\left(\cos \varphi_{1}-\cos \varphi_{3}\right) \\
& \text { Inclined } M D=R_{1} \varphi_{1}+T+R_{2} \varphi_{2}
\end{aligned}
$$$$
\text { Departure of the REACH }=\text { REACH } x \sin \varphi_{3}
$$

$$
\text { Change in TVD of the REACH }=\text { REACH } x \cos \varphi_{3}
$$

Where:

Reach $=$ The along the hole distance (MD) of portion of the hole which is normal thought to be horizontal

$\mathrm{MD}=$ Measured depth, $\mathrm{ft}$.

Dep $=$ Departure length, $\mathrm{ft}$.

$\mathrm{T}=$ Tangent length, $\mathrm{ft}$.

$\mathrm{R}_{1}=$ Radius of curvature for upper build, $\mathrm{ft}$.

$\mathrm{R}_{2}=$ Radius of curvature for lower build, $\mathrm{ft}$.

$\phi=$ Inclination angle for position 1,2 , and $3\left(\phi_{3}=90^{\circ}\right)$, degrees

Figure 1 shows the various terms and abbreviations given in these equations, which and can be solved simultaneously to determine KOP. The resulting problems during planning a horizontal turn and vertical turn in the horizontal section of the planned wellbore can be determined and solve during Mitchell ${ }^{2}$ mathematical equations and programs.

\section{Selection of mud weights for horizontal wellbore}

Mud weight selection methods used in vertical wells cannot be used in directional or horizontal holes. Therefore, $\mathrm{Mitchel}^{2}$ suggested the following equation for selecting mud densities (ppg) to stabilize drill holes:

$M W_{\text {horizontal }}=M W_{\text {vertical }}+(O B W-L O T) \frac{1-\cos 2 \varphi}{1.6}$

Where:

$\mathrm{WM}=$ Mud weight, ppg

OBW $=$ Overburden weight (Overburden stress), ppg

LOT= Leak off test value, ppg

$\phi=$ Inclination, degrees

\section{Three dimensional well profiles for a wellbore trajectory}

The design planning of the wellbore is required to construct a smooth $3 \mathrm{D}$ path that connects a surface or subsurface location to a known target or targets. In addition to 3D geometric requirements, the designer must also consider other factors related to the drilling process, such as drill string mechanical integrity, wellbore stability, cuttings transport, cementing and perforating operations, and running of casing. ${ }^{6}$ For the purpose of well-path optimization, minimum drilling cost or minimum drilling time is usually used as the optimization criterion. The design process frequently requires a few iterations before the desired solution is found. Five methods can be used to design a 3D well path. The five methods ${ }^{11}$ are average angle method (AAM), radius of curvature (RCM), constant build and turn rate (CBTM), constant curvature and build rate (CCBM) (constant tool face), and minimum curvature method (MCM). 3D geometric considerations and a discussion of these methods are presented by Azar and Samuel, ${ }^{1}$ Mitchell, ${ }^{2}$ Bourgoyn, ${ }^{3}$ Hossain and Al-Majed, ${ }^{4}$ Rabia, ${ }^{5}$ and Mitchell and Miska. ${ }^{6}$ However, MCM is the most commonly used by the petroleum industry for both well trajectory planning and directional survey evaluation. ${ }^{6}$

\section{The Minimum Curvature Method (MCM)}

MCM was originally proposed by Taylor and Mason ${ }^{7}$ and by Zaremba ${ }^{8}$ as a way to improve directional-survey analyses. Zaremba used the term circular-arc method and carried out the development using the method of vectors. Recently, Sawaryn and Thorogood ${ }^{9}$ published useful algorithms for directional well planning and deflection tool orientation. The final MCM equations which were used in optimizing wellbore trajectory are:

$$
\begin{aligned}
& R F=\frac{\Delta M D}{\beta} \tan \frac{\beta}{2} \\
& \Delta X=\left(\sin \varphi_{1} \cos \vartheta_{1}+\sin \varphi_{2} \cos \vartheta_{2}\right) R F
\end{aligned}
$$


$\Delta Y=\left(\sin \varphi_{1} \sin \vartheta_{1}+\sin \varphi_{2} \sin \vartheta_{2}\right) R F$

$\Delta Z=\left(\cos \varphi_{1}+\cos \varphi_{2}\right) R F$

Where

$\mathrm{RF}=$ Ratio Factor

$\beta=$ Dog-leg angle, degrees

$\phi=$ inclination angle, degrees

$\vartheta=$ Azimuth angle, degrees

\section{Wellbore Trajectory Optimization}

Trajectory optimization is a fundamental aspect of a wellbore design. An optimized wellbore trajectory enables drilling to be performed under minimum geostress loads and promotes a longer service life for wellbores. Trajectory optimization is particularly significant to projects in which wellbores are designed with reference to a given platform. Consequently, the necessity for trajectory optimization increases with the constraint of a fixed surface location to an irregular reservoir geometry. Despite the importance of trajectory optimization, the published articles on this subject are scarce or not available. In this work, several methods are adopted to evaluate the advantages of each possible choice of wellbore trajectory. A key issue is the choice of mechanical insitu stresses as an index for determining wellbore stability. Hole is planned from offset well data $\left(\sigma_{v}, \sigma_{\text {hmin }}, \log \right.$ correlations to strength data, $\mathrm{p}_{\mathrm{o}}$, and logs data). To increase wellbore stability, the best well orientation is that which minimizes the principal stress difference normal to the axis. In a relaxed (non-tectonic) basin where $\left(\sigma_{\mathrm{v}}>\sigma_{\text {hmin }} \sim \sigma_{\text {HMAX }}\right)$, vertical wells are the most stable wellbores. In other words, vertical holes are subjected to lower shear stresses; therefore they are generally more stable than horizontal holes. In a tectonic basin, the best well orientation is practically dependent on insitu stresses estimation. For example:If $\sigma_{\text {HMAX }}>\sigma_{\mathrm{v}}>\sigma_{\text {hmin }}$, we still have to know the specific values to decide the best trajectory, If $\sigma_{\text {HMAX }}$ $=0.75 \mathrm{psi} / \mathrm{ft}, \sigma_{\mathrm{v}}=0.56 \mathrm{psi} / \mathrm{ft}, \sigma_{\mathrm{hmin}}=0.44 \mathrm{psi} / \mathrm{ft}$., a horizontal well parallel to $\sigma_{\text {HMAX }}$ is the best optimized profile, and If $\sigma_{\text {HMAX }}=0.75, \sigma_{\mathrm{v}}$ $=0.65, \sigma_{\text {hmin }}=0.44 \mathrm{psi} / \mathrm{ft}$., a horizontal hole parallel to $\sigma_{\text {hmin }}$ is likely the best optimized wellbore. Consequently, careful rock mechanics analysis is the best method for wellbore trajectory selection. The best orientation which minimizes the principal stress difference normal to the axis increases wellbore stability. To predict rock mechanics stability, Mitchell ${ }^{2}$ presented a borehole stability method for vertical and inclined wells, and the general methodology for analysis of wellbore stability has already been discussed. Yi et al. ${ }^{10}$ built the GEM to predict wellbore stability using the following equations to determine insitu stresses:

$$
\begin{aligned}
& \sigma_{v}=\int_{0}^{H} \rho_{b}(h) d h \\
& \sigma_{h}=\frac{v}{1-v}\left(\sigma_{v}-\alpha_{b} P_{p}\right)+\alpha_{b} P_{p}
\end{aligned}
$$

Where

$\sigma_{\mathrm{v}}=$ Overburden stress, psi $\sigma_{\mathrm{h}}=$ Minimum horizontal stress, $\mathrm{psi}$

$\rho_{\mathrm{b}}=$ Bulk density for rock, $\mathrm{lb} / \mathrm{ft}^{3}{ }^{3}$

$\mathrm{h}=$ depth, $\mathrm{ft}$.

$v=$ Possion's ratio

$\alpha_{\mathrm{b}}=$ Biot Coefficient

$\mathrm{P}_{\mathrm{p}}=$ Pore pressure, $\mathrm{psi}$

Maximum horizontal stress magnitude and orientation can be determined from the inversion of calibration of borehole failure such as breakouts, washouts, drilling induced fractures and drilling problems. ${ }^{10}$ Additionally, wellbore stability models used for horizontal and deviated wells are presented by Manshad et al., ${ }^{11}$ Mohiuddin et al., ${ }^{12}$ and Yi et al., ${ }^{10}$. The role of rock strength criteria in wellbore stability and trajectory optimization is presented by Chabook et al. ${ }^{13} \mathrm{~A}$ combination of all above mentioned methods will be used to stabilize and optimize the horizontal wellbore.

\section{Horizontal Well Data}

Horizontal wellbore is required to drill $12.25^{\prime}$ hole vertical to 6200 $\mathrm{ft}$. then start building to $39.83^{\circ}$ inclination along $177.83^{\circ}$ azimuth at $7192 \mathrm{ft}$. with $4^{\circ} \mathrm{dog}-\mathrm{leg}$, then keep holding with the same inclination and azimuth to $7404 \mathrm{ft}$. Drilling was continued for building curve section in $81 / 2$ " hole with $5.5^{\circ} \mathrm{dog}$-leg to landing point at $\mathrm{MD}=8519$ $\mathrm{ft}$., TVD $=7773.4 \mathrm{ft}$.and with $88^{\circ}$ inclination along $132^{\circ}$ azimuth. After that,keep holding with same to $8608.9 \mathrm{ft}$., and start building with $1.5^{\circ} \mathrm{dog}$-leg till building $89^{\circ}$ inclination along $128^{\circ}$ azimuth until reaching to $9979 \mathrm{ft}$. horizontally. Formation tops, MCM calculations, and casing points selection for planned horizontal well passed through 5 targets after applying the above methods are shown in Figure (2) and Table (1). More details of the horizontal well data are published by Halafawi and Avram. ${ }^{14}$

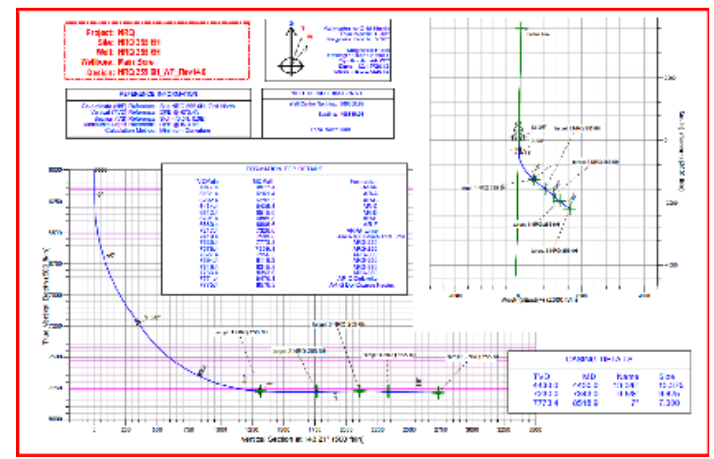

Figure 2 Formation Tops, side view, plan view, and casing points for planned horizontal well passed through 5 targets

\section{Results and Discussion}

In well-trajectory design, the coordinates of the initial point and targetpoint are selected to pass through 5 targets: NRQ $2556 \mathrm{H}-1$, NRQ 255 6H-2, NRQ 255 6H-3, NRQ 255 6H-4, and NRQ 255 6H-5. Using MCM to build the optimum survey trajectory for horizontal hole, it resulted in $\mathrm{MD}=8560.5 \mathrm{ft}$., $\mathrm{I}=88^{\circ}, \mathrm{A}=133^{\circ}, \mathrm{TVD}=7773.4 \mathrm{ft}$. for NRQ $2556 \mathrm{H}-1 ; \mathrm{MD}=9024.8 \mathrm{ft}$., $\mathrm{I}=90.92^{\circ}, \mathrm{A}=128.28^{\circ} \mathrm{TVD}=7778.4 \mathrm{ft}$. for NRQ $2556 \mathrm{H}-2 ; \mathrm{MD}=9373.9 \mathrm{ft}$., $\mathrm{I}=90.80^{\circ}, \mathrm{A}=126.28^{\circ}, \mathrm{TVD}=7773.4$ ft. for NRQ $2556 \mathrm{H}-3 ; \mathrm{MD}=9613.8 \mathrm{ft} ., \quad \mathrm{I}=87.72^{\circ}, \mathrm{A}=127.23^{\circ}$, $\mathrm{TVD}=7778.4 \mathrm{ft}$. for NRQ $2556 \mathrm{H}-4$; and $\mathrm{MD}=10021 \mathrm{ft}$., $\mathrm{I}=89.11^{\circ}$, 
$\mathrm{A}=128.78^{\circ}, \mathrm{TVD}=7786.4 \mathrm{ft}$. for NRQ $2556 \mathrm{H}-5$. Vertical side view, plan view, and casing points are shown in Figure 2 for the planned horizontal wellbore.

Tables 1-3 show MCM calculations and results for horizontal wellbore surveying. Figures 3-5 show the planned wellbore trajectory versus the real trajectory for drilling each casing point section. There is no difference between the planned and the real trajectories for sections 1 and 2 where $13.375 "(133 / 8 ")$ and $9.625 "$ " (9 5/8") casings are landed to $\mathrm{TVD}=4694.1 \mathrm{ft}$., $\mathrm{MD}=4695 \mathrm{ft}$.and $\mathrm{TVD}=7230 \mathrm{ft}$. $\mathrm{MD}=7343.6 \mathrm{ft}$. respectively (Figure 3). Therefore, the design wellbore trajectory is optimum without major instability problems until $\mathrm{MD}=7343.6 \mathrm{ft}$.

Table I MCM calculations and results for planned horizontal well passed through 5 targets

\begin{tabular}{llllllllll}
\hline MD & $\phi$ & 9 & TVD & $+\mathbf{N} /-\mathbf{S}$ & $\mathbf{+}$ E/-W & Dleg & TFace & $\mathbf{V}_{\text {SectTarget }}$ & \\
\hline 0 & 0 & 0 & 0 & 0 & 0 & 0 & 0 & 0 & \\
6200 & 0 & 0 & 6200 & 0 & 0 & 0 & 0 & 0 & \\
7192 & 39.83 & 177.83 & 7114 & -330.9 & 12.5 & $4.0 \mid$ & 177.83 & 272.5 & \\
7403.7 & 39.83 & 177.83 & 7276.6 & -466.4 & 17.6 & 0 & 0 & 384.1 & \\
8518.9 & 88 & 132 & 7773.4 & -1276.2 & 492.2 & 5.54 & -54.44 & 1316.8 & target I \\
8608.9 & 88 & 132 & 7776.5 & -1336.4 & 559 & 0 & 0 & 1405 & \\
8917.2 & 90.92 & 128.02 & 7779.4 & -1534.5 & 795 & 1.6 & -53.74 & 1705 & \\
8982.6 & 90.92 & 128.02 & 7778.4 & -1574.8 & 846.5 & 0 & 0 & 1768.1 & target 2 \\
9006 & 90.82 & 127.69 & 7778 & -1589.2 & 865.1 & 1.5 & -107 & 1790.7 & \\
9332 & 90.82 & 127.69 & 7773.4 & -1788.4 & 1123 & 0 & 0 & 2104.8 & target 3 \\
9496.7 & 87.69 & 127.73 & 7775.5 & -1889.1 & 1253.2 & 1.9 & 179.15 & 2263.4 & \\
9567.4 & 87.69 & 127.73 & 7778.4 & -1932.4 & 1309.1 & 0 & 0 & 2331.5 & target 4 \\
9657.7 & 89.03 & 127.89 & $778 \mid$ & -1987.7 & 1380.4 & 1.5 & 6.75 & $24 \mid 8.5$ & \\
9979 & 89.03 & 127.89 & 7786.4 & -2185 & 1633.9 & 0 & 0 & 2728.3 & target 5 \\
\hline
\end{tabular}

Table 2 MCM calculations and results for horizontal wellbore section I and 2.

\begin{tabular}{|c|c|c|c|c|c|c|c|c|c|}
\hline MD & $\phi$ & 9 & TVD & $+\mathrm{N} /-\mathrm{S}$ & $+E /-W$ & Dleg & $\mathbf{T}_{\text {Face }}$ & $\mathbf{V}_{\text {SectTarget }}$ & \\
\hline 7306 & 37.57 & 177.17 & 7203.2 & -375.3 & 11.1 & 0 & 0 & 305.5 & \\
\hline 7321 & 38.86 & 175.14 & 7215 & -384.5 & 11.7 & 12 & -45 & 313.3 & \\
\hline 7341 & 38.86 & 175.14 & 7230.5 & -397 & 12.8 & 0 & 0 & 323.9 & \\
\hline 7766.1 & 43 & 125 & 7560.4 & -619.1 & 146.4 & 7.64 & -102.8 & 581.5 & \\
\hline 8420.4 & 91.08 & 131.69 & 7808.4 & -986.7 & 600.8 & 7.4 & 8.95 & II49.| & Target I ST- I \\
\hline 8510.4 & 91.08 & 131.69 & 7806.7 & -1046.6 & 668 & 0 & 0 & 1237.4 & \\
\hline 8527.8 & 91.12 & 131.95 & 7806.4 & -1058.2 & 681 & 1.5 & 82.22 & 1254.6 & \\
\hline 8935.1 & 91.12 & 131.95 & 7798.4 & -1330.4 & 983.8 & 0 & 0 & 1654.5 & Target 2 ST-I \\
\hline 9116.8 & 90.28 & 134.54 & 7796.2 & -1454.9 & 1116.2 & 1.5 & 107.89 & 1833.7 & \\
\hline 9274.8 & 90.28 & 134.54 & 7795.4 & -1565.7 & 1228.8 & 0 & 0 & 1990 & Target 3 ST-I \\
\hline 9579.4 & 88.99 & 140.5 & 7797.3 & -1790.2 & 1434.4 & 2 & 102.22 & 2293.2 & \\
\hline 9640.3 & 88.99 & 140.5 & 7798.4 & -1837.2 & 1473.1 & 0 & 0 & 2354.1 & Target 4 ST-I \\
\hline 10062.5 & 89.56 & 148.92 & 7803.7 & -2181.5 & 1716.8 & 2 & 86.22 & 2775.6 & \\
\hline 10148.1 & 89.56 & 148.92 & 7804.4 & -2254.8 & $|76|$ & 0 & 0 & 2860.7 & Target I ST- I \\
\hline
\end{tabular}

Table 3 MCM calculations and results for sidetracking hole

\begin{tabular}{ccccccccc}
\hline MD & $\phi$ & $\boldsymbol{9}$ & TVD & $+\mathbf{N} /-\mathbf{S}$ & + E/-W & Dleg & $\mathbf{T}_{\text {Face }}$ & $\mathbf{V}_{\text {SectTarget }}$ \\
\hline 7306 & 37.57 & 177.17 & 7203.2 & -375.3 & 11.1 & 0 & 0 & 307.2 \\
7402 & 41.5 & 177.17 & 7277.2 & -436.3 & 14.1 & 4.09 & 0 & 357.9 \\
\hline
\end{tabular}




\begin{tabular}{|c|c|c|c|c|c|c|c|c|c|}
\hline \multicolumn{10}{|c|}{ (Table 3 continue...) } \\
\hline 7460 & 41.5 & 177.17 & 7320.7 & -474.7 & 16 & 0 & 0 & 389.7 & \\
\hline 8452 & 85.7 & 134.5 & 7767 & -1211.9 & 419 & 5.76 & -53.54 & 1221.5 & \\
\hline 8552.6 & 87 & 132 & 7773.4 & -1280.6 & 492.1 & 2.8 & -62.56 & 1320.3 & \\
\hline 8642.6 & 87 & 132 & 7778.1 & -1340.7 & 558.9 & 0 & 0 & 1408.4 & \\
\hline 8923.8 & 91.77 & 129.01 & 7781.2 & -1523.3 & 772.6 & 2 & -32.11 & 1682.7 & \\
\hline 9013.1 & 91.77 & 129.01 & 7778.4 & -1579.5 & 842 & 0 & 0 & 1769.2 & target 2 \\
\hline 9256.5 & 90.31 & 125.14 & 7774 & -1726.2 & 1036.1 & 1.7 & -110.6 & 2002.9 & \\
\hline 9364 & 90.31 & 125.14 & 7773.4 & -1788.1 & 1124 & 0 & 0 & 2105.1 & target 3 \\
\hline 9541.5 & 87.94 & 127.78 & 7776.1 & -1893.5 & 1266.7 & 2 & 131.86 & 2275 & \\
\hline 9605.5 & 87.94 & 127.78 & 7778.4 & -1932.7 & 1317.3 & 0 & 0 & 2336.6 & target 4 \\
\hline 9695.6 & 88.98 & 128.65 & 7780.8 & -1988.4 & 1388.1 & 1.5 & 39.67 & 2423.7 & \\
\hline 10010.4 & 88.98 & 128.65 & 7786.4 & -2185 & 1633.9 & 0 & 0 & 2728.3 & target 5 \\
\hline
\end{tabular}

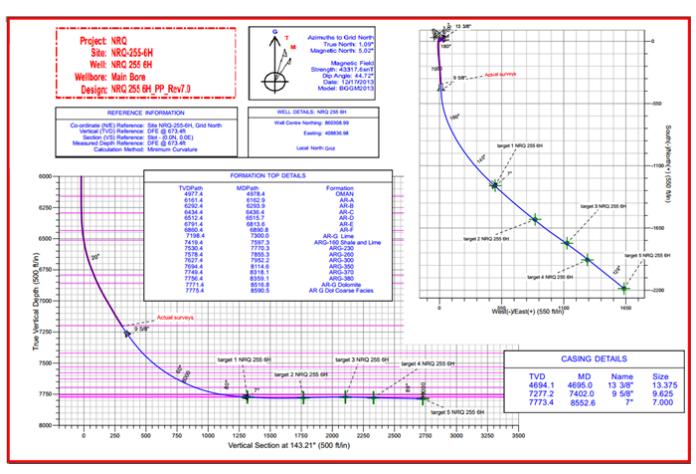

Figure 3 Formation Tops, side view, plan view, and casing points for horizontal wellbore- the planned versus the reality- section land section 2

During drilling 8.5" casing hole, the drillstring was stuck. Firstly, during drilling 8.5 " hole; and after the driller performed the following actions:

\section{- Picking up $(\mathrm{P} / \mathrm{U})$ in $81 / 2$ " hole}

- Reaming bottom hole assembly (BHA) after 7" Liner (LNR) got held-up @ 8240’ MD, Pulling out of hole (POOH)with LNR

- Re-Runing Tricone Insert (RR TCI) Bit size 8 1/2" dressed with $3 \times 18$ Jets and $63 / 4$ " measurement while drilling (MWD) tools,

Then, the shallow testwas done and found OK. Secondly, during runningin hole to $7780 \mathrm{ft}$., a resistance was found. After the decision

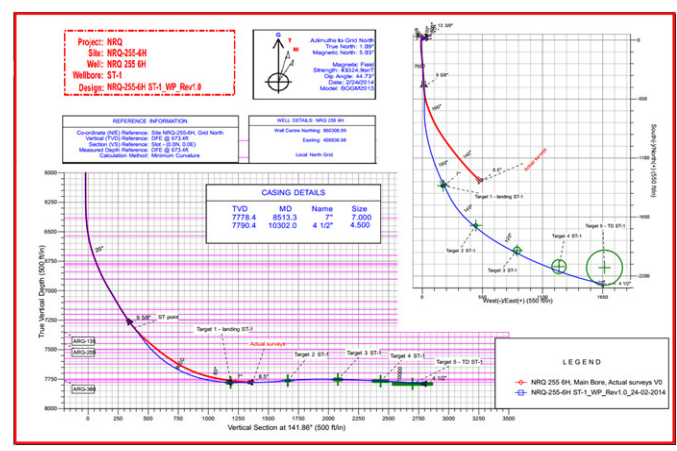

Figure 4 Sidetracking hole, side view, plan view, and casing points for horizontal well- the planned versus the reality- section 3 was to ream down with 40RPM, 490gpm, SPP 3050psi, and 3000$5000 \mathrm{ft} . / \mathrm{lb}$ to $8070 \mathrm{ft}$. and make circulation as a first action to remediate the problem, shaker was found continuously loaded with lumps of caved shale. Several pack offs were also noticed. After that, Resuming harder reaming down as a second action to rapidly treat the problem, but shaker was also found continuously heavily loaded with shale lumps, several pack offs were also noticed, and sudden severe mud losses at $8290 \mathrm{ft}$. were also occurred. Finally, POOH for cement plug decision was taken to pump two cement plugs. The cement was then drilled to $7305 \mathrm{ft}$. Whipstock was run in hole and a window from 7305 to $7315 \mathrm{ft} .4 \mathrm{ft}$.was milled of the new formation was drilled to $7719 \mathrm{ft}$. (the last foot drilled in $3 \mathrm{hrs}$ ). Sidetracking happened due to poor wellbore stability determination (Figure 4).

However, logging while drilling (LWD) data and drilling data were used to build new a GEM and wellbore stability model accompanied by MCM to optimize and update sidetracking profile to enter the five targets horizontally. In-situ stresses $\left(\sigma_{x}, \sigma_{y}, \sigma_{z}\right)$ were, firstly, determined, these stresses were transferred to radial stresses $\left(\sigma_{\mathrm{r}}, \sigma_{\theta}\right.$, $\sigma_{z}$ ), the GEM was constructed, and then the best wellbore orientation was selected.Finally, the safe mud window was determined and the optimum trajectory was selected. After updating wellbore stability for wellbore,the 6" sidetracking wellbore entered the 5 targets horizontally at $\mathrm{MD}=10010.4 \mathrm{ft}$., $\mathrm{I}=88.89^{\circ}, \mathrm{A}=128.65^{\circ}, \mathrm{TVD}=7786.4$ $\mathrm{ft}$. as planned without any other major instability problems as shown in Figures 4 and 5.The planned horizontal trajectory became matched with the real trajectory (Figure 5).

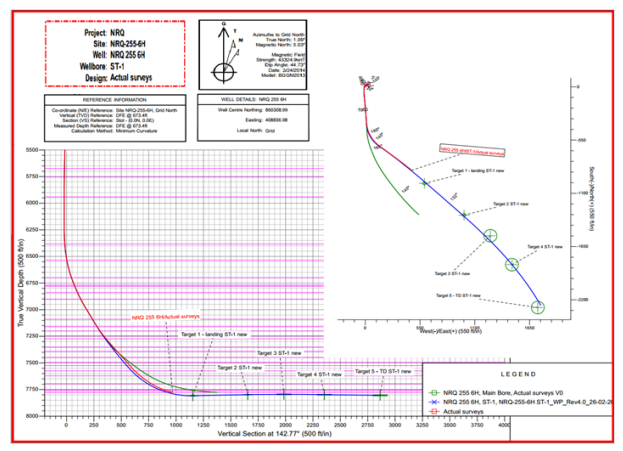

Figure 5 Final horizontal well trajectory- the planned versus the reality 


\section{Conclusions and Recommendations}

Based on the results and analysis, the following conclusions are extracted:

1. A long radius horizontal wellbore profile was successfully optimized for planned wellbore which matched with real data.

2. MCM was proved its success in optimizing horizontal wellbore profile.

3. Rock mechanics and wellbore stability are key elements for drilling the long radius horizontal wellbore without major problems.

4. The best wellbore orientation was successfully selected while drilling sidetracking hole to hit the five targets horizontally without wellbore instability problems.

5. Wellbore stability models and GEM are recommended for selecting and design horizontal wellbore trajectory.

\section{References}

1. Azar JJ, Samuel GR. Drilling Engineering. PennWell books; 2007.

2. Mitchell BJ. Advanced Oil Well Drilling Engineering Handbook and Computer Programs. 10th ed. United Kingdom: Mitchell Engineering Publishing; 1995.

3. Bourgoyn AT, Millheim KK, Chenevert ME, Young FS. Applied drilling engineering. SPE Textbook Series. 1991;2.

4. Hossain ME, Al-Majed AA. Fundamentals of Sustainable Drilling Engineering. John Wiley \& Sons; 2015.

5. Rabia H. Well Engineering \& Construction. London: Entrac Consulting Limited; 2002.
6. Mitchell RF, Miska SZ. Fundamentals of Drilling Engineering. Society of Petroleum Engineers; 2011.

7. Taylor HL, Mason MC. A systematic approach to well surveying calculations. Society of Petroleum Engineers Journal. 1972;12(06):474 488.

8. Zaremba WA. Directional survey by the circular arc method. Society of Petroleum Engineers Journal. 1973;13(01):5-11.

9. Sawaryn SJ, Thorogood JL. A compendium of directional calculations based on the minimum curvature method. In: SPE Annual Technical Conference and Exhibition. Society of Petroleum Engineers; 2003.

10. Yi X, Goodman HE, Williams RS, Hilarides WK. Building a geomechanical model for Kotabatak field with applications to sanding onset and wellbore stability predictions. In: IADC/SPE Asia Pacific Drilling Technology Conference and Exhibition. Society of Petroleum Engineers; 2008.

11. Manshad AK, Jalalifar H, Aslannejad M. Analysis of vertical, horizontal and deviated wellbores stability by analytical and numerical methods. Journal of Petroleum Exploration and Production Technology. 2014;4(4):359-369.

12. Mohiuddin MA, Khan K, Abdulraheem A, Al-Majed A, Awal MR. Analysis of wellbore instability in vertical, directional, and horizontal wells using field data. Journal of petroleum Science and Engineering. 2007;55(1-2):83-92.

13. Chabook M, Al-Ajmi A, Isaev V. The role of rock strength criteria in wellbore stability and trajectory optimization. International Journal of Rock Mechanics and Mining Sciences. 2015;(80):373-378.

14. Halafawi M, Avram L. Wellbore, BHA, Motor/Rotary Steerable, and Bits Statistical Performance Analyses for Drilling Horizontal Wells. In: Romania: BuletinulUniversităţii Petrol-Gaze din Ploieşti - SeriaTehnică; 2018 . 